\title{
DESARROLLO. PALEONTOLOGÍA (POLÍTICA) DE UNA IDEA (NEOLIBERAL)
}

\section{José Francisco Puello-Socarrás*}

RESUMEN: La impronta colonial del neoliberalismo puede rastrearse desde las reflexiones suscitadas por la Sociedad Mont-Pèlerin, primer escenario oficial neoliberal y cónclave que evoluciona en paralelo al periodo de descolonización de posguerra del siglo $\mathrm{xx}$ de la mano de la tesis acerca del desarrollo colonial sostenida por los países colonizadores. Gestada inauguralmente bajo esta perspectiva, la idea de desarrollo, sin adjetivos, resultaría ser una idea-guía característica del neoliberalismo, así como el referente crucial para materializar este paradigma socioeconómico, su proyecto político y su hegemonía a nivel global durante el último cuarto del siglo xx e, incluso, hoy en el nuevo milenio. En vista de que dos referencias centrales en este debate, tanto la arqueología realizada por Wolfgang Sachs, como la genealogía propuesta por Escobar, sobre la idea de desarrollo, fallan en establecer los vínculos estrechos que existen entre la emergencia/procedencia de esta idea y su origen eminentemente neoliberal, esta propuesta pretende ensayar una paleontología (politológica) del desarrollo «excavando» con mayor profundidad en las razones y en los argumentos de tal acontecimiento con el fin de reconstruir complementariamente la conceptualización del desarrollo como una construcción propia de la ideología y praxis neoliberales.

PALABRAS CLAVE: desarrollo, subdesarrollo, neoliberalismo, colonialismo, nuevo neoliberalismo.

* Docente de la Escuela Superior de Administración Pública (eSAP), Colombia. 
ABSTRACT: Neoliberalism's colonial footprint can be traced back to the thinking that originated with the Mont Pelerin Society, neoliberalism's official headquarters and the conclave that evolved in parallel to the 20th Century's post-war period of decolonization with a basis in the thesis of colonial development held by the colonizing countries. Initially conceived from this perspective, the idea of development, without adjectives, would come to be an idea-guide chracteristic of neoliberalism. Similarly, the crucial aspects in bringing this socioeconomic paradigm to fruition are its political project and its global hegemony during the last quarter of the 20th Century and now in the new millennium. Given that two key works in this debate, arqueología by Wolfgang Sachs and genealogia by Escobar on the concept of development failed to establish the strong ties that exist between the emergence/origin of this concept and its eminently neoliberal origin, this article intends to explore a paleontology (political science) of development, «digging» deeper into the reasons and arguments of the issue with the aim of reconstructing, complementarily, the conceptualization of development as a product of neoliberal ideology and praxis.

KEY WORDS: development, underdevelopment, neoliberalism, colonialism, new neoliberalism. 


\section{EL DESARROLLO EN SU FRAGUA}

U

na de la tesis más ensombrecidas sobre el neoliberalismo, en la que existen grandes deficiencias análiticas, es la reflexión sobre su naturaleza colonialista (Puello-Socarrás, 2013). ${ }^{1}$ Esta raíz inherente al neoliberalismo se expresa de diversas maneras. Aquí nos limitamos a esbozar dos dimensiones fundamentales: 1) el componente colonial in vitro del pensamiento político e ideológico neoliberales (nivel que ampliaremos con mayor detalle); y, subsidiariamente, 2) el neoliberalismo neocolonial in vivo en tanto condición concreta.

Desde un principio la impronta colonial del neoliberalismo puede rastrearse en las reflexiones inaugurales suscitadas por la Sociedad MontPèlerin, foro neoliberal $a b$ origine que evoluciona paralelo al periodo de descolonización de posguerras en el siglo xx - especialmente en África- y posiciona ideológica y políticamente la tesis acerca del desarrollo colonial sostenida por los propios países colonizadores. A través de este marco histórico es posible establecer de qué manera se construye el núcleo colonialista en el interior del neoliberalismo y las modalidades bajo las cuales ha sido difundido.

La expresión más fundamental dentro de este acontecimiento es la creación y recreación de la idea de desarrollo. Omitiendo directamente el adjetivo colonial aunque no su contenido, el desarrollo ha sido presentado como un horizonte liberador, incluso emancipador, que aseguraría la paz social perpetua. Por ello, simultáneamente se ha visto como una fatalidad dentro de los procesos de modernización en el marco de los valores del capitalismo tardío contemporáneo (Boron, 2008: 19-23; Roffinelli y Kohan, 2003). ${ }^{2}$ No sin razón, el aclamado - y también

${ }^{1}$ Nos referimos a «colonialismo» en sentido complejo y plural, en términos análogos a los de Prada (2013) y al concepto de colonialidad múltiple: colonialidades del poder, cuerpo, género, sobre todo, colonialidades del saber y económica, teniendo también como referencia el colonialismo externo e interno propuesto por González (1963; 2006).

${ }^{2}$ Una obra que estilizó ideológicamente estos presupuestos fue la de Walter Rostow, Las etapas del crecimiento económico, subtitulada muy suspicazmente: Un manifiesto no comunista, publicada en 1960. 
supuesto - triunfo definitivo del capitalismo en el ocaso del siglo $\mathrm{xx}$, tras el derrumbe del llamado socialismo real, agitó la sensación según la cual el capitalismo en su variante neoliberal sería la fase superior de la civilización humana, histórica y cualitativamente hablando; el último hombre y el fin de la historia, según sugirió Francis Fukuyama. ${ }^{3}$

Más allá de la reflexión estrictamente filosófica sobre este asunto, el desarrollo y su correlato, la noción de subdesarrollo - eufemismos que actualizan en positivo y en negativo la idea-fuerza más sustancial del capitalismo histórico: el progreso- proceden y emergen originalmente en el interior y desde los márgenes del neoliberalismo naciente.

Con el paso del tiempo, la idea/noción/concepto de desarrollo/subdesarrollo se convertiría en un campo de intensas disputas políticas e ideológicas protagonizadas por diversas tradiciones de pensamiento social, en general, y por las teorías económicas, en particular. Por ello, reconocer, rescatar y reincorporar los orígenes del desarrollo como idea permite restablecer y enriquecer todavía más las acaloradas discusiones que, hoy por hoy, giran no sólo alrededor de supuestas novas pro-desarrollistas sino, más importante aún, frente a la desestimación y abandono de la idea misma de desarrollo tal y como lo vienen planteando varios enfoques emergentes que autoproclaman un «más allá» del desarrollo, o que también son reconocidos más recientemente como post-desarrollistas (véase Escobar, 2005).

Aun cuando existe al día de hoy una larga tradición crítica que ha develado el carácter eminentemente colonialista de la idea de desarrollo (véase Sachs, 1996, 1999; Escobar, 2007), sigue sin enfatizarse con contundencia que el desarrollo y el subdesarrollo son conceptos neoliberales.

${ }^{3}$ Dos antecedentes de esta postura se encuentran, primero, en David Ricardo, en los albores del siglo xix y la idea sobre el «estancamiento final» de la civilización en el capitalismo y, segundo, en Karl Polanyi — no hay que dejar de subrayarlo, hermano de uno de los cofundadores de la Sociedad Mont-Pèlerin- quien, en La Gran transformación (1944), anticipara el fin de la Historia humana en la sociedad capitalista. Desde luego, esta noción ha estado rondando el pensamiento pro-capitalista muchísimo tiempo antes de que el bestseller de Francis Fukuyama «cautivara» al mundo. 
Sin ser obtusamente abrasivos respecto a la literatura hasta hoy disponible, un caleidoscopio actualizado sobre este particular permite identificar este déficit (Veltmeyer, Fara y Ampuero, 2011; Parpart y Veltmeyer, 2011). Esta cuestión se torna más sugestiva al comprobar que dos enfoques recurridos e imposibles de omitir en los análisis críticos sobre el desarrollo - la arqueología realizada por Wolfgang Sachs y la genealogía propuesta por Arturo Escobar como parte de la invención del tercer mundo - fallan en registrar el origen, la evolución y las proyecciones del desarrollo/subdesarrollo como una idea vinculada estrechamente con el neoliberalismo y los trasfondos sociopolíticos que implican sus praxis.

Esta dificultad analítica responde a varias situaciones. Primero, advertimos un obstáculo central que es preciso tener muy presente en relación con la diversidad constitutiva en el interior - al menosde dos posturas neoliberales: la diferencia entre el fundamentalismo ortodoxo de mercado y aquellos que profesan que el mercado es fundamental bajo una mirada neoliberal aunque heterodoxa. Enseguida, convocamos esta dicotomía ortodoxia/heterodoxia para reconocer las procedencias neoliberales de la idea del desarrollo. Finalmente, proponemos algunas conclusiones respecto a los cuestionamientos sobre esta idea, teniendo en cuenta que los aportes realizados podrían sugerir un nuevo horizonte de visibilidad respecto a los aspectos más sustanciales en el «cambio de época» por el cual atraviesa esta discusión y el cuestionamiento de la cuestión del desarrollo en América Latina y el Caribe hoy.

\section{ORTODOXIA/HETERODOXIA NEOLIBERALES:}

HACIA UNA NUEVA DICOTOMÍA

Comúnmente, los estudios críticos sugieren los vínculos del desarrollo con los enfoques neoclásicos de la teoría económica. Sin embargo, estos enfoques son entendidos bajo una versión que si bien no resulta equivocada sí 
resulta demasiado restrictiva, pues agota el universo de «lo neoclásico» en sus núcleos ortodoxos más convencionales (especialmente las escuelas de pensamiento y teorías económicas de raigambre angloamericano), sin considerar la existencia e influencias de todo tipo (teóricas, epistemológicas y, desde luego, político-ideológicas) de variantes heterodoxas de cuño europeo continental de la teoría neoclásica: las escuelas austriacas o alemanas. Esa operación omite las contribuciones que las escuelas heterodoxas han realizado a la constitución del pensamiento neoliberal y, por lo tanto, figuran como claves interpretativas imposibles de perder de vista a la hora de comprender la emergencia del neoliberalismo desde mediados del siglo xx y su ulterior despliegue, incluso hasta la actualidad (Puello-Socarrás, 2008, 2011 y 2014).

Restringir los enfoques neoclásicos exclusivamente a sus variantes ortodoxas reforzaría - sobre todo en el terreno de la teoría y el pensamiento económicos - la falaz dicotomía entre ortodoxia/heterodoxia usualmente invocada para describir el carácter y el contenido ideológico de los enfoques económicos, igualando lo ortodoxo con lo neoliberal y relacionando equivocadamente lo heterodoxo con enfoques considerados no neoliberales. Bajo esta división, las corrientes heterodoxas neoclásicas (insistimos: las posturas austriacas o alemanas que hacen parte de la mundovisión neoclásica y del neoliberalismo in extenso) podrían estar (con)fundidas indistintamente con enfoques keynesianos o marxistas (véase por ejemplo Cypher, 2011).

En estos términos, la dicotomía antes comentada, además de ambigua, resulta demasiado problemática, en particular por su falta de consistencia analítica (sólo acudiendo aquí a los parámetros de la lógica formal). Para recobrar consistentemente la utilidad analítica de la dicotomía aludida, estimamos que sus extremos (dicotómicos) deben ser adecuadamente reinterpretados respecto a un centro en común, el neoliberalismo, advirtiendo la existencia de un neoliberalismo ortodoxo y un neoliberalismo beterodoxo. Uno y otro se distinguen, en primer lugar, a partir de sus respectivas influencias hegemónicas en el interior del neoliberalismo, o lo que es lo mismo: discerniendo entre las corrientes 
consideradas principales (mainstream) de aquellas que no lo son y, por tanto, estas últimas valoradas como subsidiarias o subordinadas en determinados momentos históricos para la doxa neoliberal en su dimensión intra-hegemónica ${ }^{4}$ Esta operación, en segundo lugar, llevaría a registrar una dicotomía adicional entre teorías, pensamientos, ideologías, etcétera, de carácter neoliberal y otros de índole no neoliberal ( $v_{*} g r_{*}$, keynesianismo, marxismo).

Teniendo en cuenta lo anterior, y a partir de lo documentado recientemente por Plehwe (2009), es posible entonces ensayar - si se permite la homología - una paleontología de la idea del desarrollo/subdesarrollo «escavando» sobre las condiciones políticas y los argumentos ideológicos que hicieron parte de su surgimiento y proyección, con el fin de comprender en qué sentido esta idea se constituye en una praxis discursiva neoliberal generada principalmente desde el punto de vista de: a) proyecto (político) estratégico: en la forma de un paradigma general y bajo un contenido específico en el capitalismo tardío; y, subsidiariamente, b) trayectorias (de políticas) tácticas y concretas.

\section{EL DESARROLLO COMO PROYECTO POLÍTICO DEL NEOLIBERALISMO}

Si bien es cierto que la invención de la dicotomía desarrollo/subdesarrollo tuvo como momento inaugural la enunciación oficial de la doctrina Truman (20 de enero de 1949), según la cual los países «más desarrollados» (del capitalismo central) mostrarían a los países «menos desarrollados» (periferias capitalistas) la vía hacia el progreso, valdría la pena recordar que desde 1947 (12 de marzo) - el mismo año en el cual el presidente estadounidense de ese momento, Harry Truman, exponía las ideas acerca del

${ }^{4}$ Esta distinción también resulta crucial a la hora de analizar las trayectorias del neoliberalismo históricas y actuales, especialmente el papel que cumplen la heterodoxia neoliberal en el más reciente giro heterodoxo del neoliberalismo en el siglo xxi (véase Puello-Socarrás, 2013). 
Plan Marshall «para proveer ayuda a Europa» — se anticipó en un discurso ante el Congreso en pleno de Estados Unidos, lo siguiente:

[...] To ensure the peaceful development of nations, free from coercion, the United States has taken a leading part in establishing the United Nations, The United Nations is designed to make possible lasting freedom and independence for all its members. We shall not realize our objectives, however, unless we are willing to help free peoples to maintain their free institutions and their national integrity against aggressive movements that seek to impose upon them totalitarian regimes. This is no more than a frank recognition that totalitarian regimes imposed on free peoples, by direct or indirect aggression, undermine the foundations of international peace and hence the security of the United States.

$[\ldots]$

I believe that it must be the policy of the United States to support free peoples who are resisting attempted subjugation by armed minorities or by outside pressures.

I believe that we must assist free peoples to work out their own destinies in their own way.

I believe that our help should be primarily through economic and financial aid which is essential to economic stability and orderly political processes (Truman, 1963: 178-179).

Un par de años más adelante, en el discurso de toma de posesión presidencial en Estados Unidos (20 de enero de 1949), Truman continuaría reiterando, en forma cada vez más incisiva, el contenido ideológico y político de la emergente idea de desarrollo.

Este acontecimiento ha sido sintetizado así por Esteva (1996: 59):

En la concepción grandiosa del discurso de Truman, no hay lugar para la precisión técnica o teórica. El emblema define un programa consciente de la llegada de Mao, que ve la evolución como antídoto de la revolución (en la tradición de Herder), aunque adopta simultáneamente el ímpetu revolucionario de que Marx [sic] dotó a la palabra. La concepción de Truman emplea a veces «desarrollo» en el sentido transitivo de los administradores coloniales británicos, a fin 
de establecer claramente la jerarquía de las iniciativas que promueve. Pero a veces pasa también con dificultad al empleo intransitivo el término, en la más refinada tradición hegeliana.

Siguiendo nuevamente la rigurosa documentación y los análisis aportados por Esteva, debe subrayarse otro antecedente fundamental dentro de este debate.

Si bien el primero en emplear la palabra desarrollo/subdesarrollo no fue Harry Truman, sino Wilfred Benson, miembro del secretariado de la Organización Internacional del Trabajo (огт), cuando en 1942 se refería al Progreso económico de las áreas subdesarrolladas, ciertamente tal designación «sólo adquirió relevancia cuando Truman la presentó como emblema de su propia política. En este contexto, adquirió una virulencia colonizadora insospechada» (Esteva, 1996:54). ${ }^{5}$ Sin embargo, continúa su relato Esteva, inmediatamente después a Benson, la expresión áreas económicamente atrasadas fue difundida teóricamente e introducida técnicamente por Paul Rosenstein-Rodan (también por Arthur Lewis) hacia 1943-1944. Hay que registrar que, cronológicamente hablando, este debut teórico de la idea de desarrollo/subdesarrollo se anticipó en más de media década a las publicaciones seminales de Raúl Prebisch: El desarrollo económico de la América Latina y algunos de sus principales problemas y Crecimiento, desequilibrio y disparidades: interpretación del proceso de desarrollo económico, las cuales datan de 1949 y 1950 , respectivamente. ${ }^{6}$

Escobar (2007: 137), deslizando esta misma indagación, aunque retrocediendo un poco más en el tiempo, señala que otro de los referentes remotos del desarrollo, en tanto idea, es la obra de Joseph Schumpeter, Theorie der wirtshaftlichen Entwicklung, publicada por primera vez

${ }^{5}$ Arndt (1987: 1) inicia su obra Desarrollo económico: la bistoria de una idea utilizando un lenguaje - diríamos - menos provocativo, pero que ilustra la magnitud de la ideología del desarrollo en tanto mundo-visión: «El mundo ha llegado a acostumbrarse a pensarse a sí mismo como dividido en países desarrollados y en vías de desarrollo».

${ }^{6}$ Puntualmente en una conferencia organizada por el Consejo Nacional de Paz de Gran Bretaña y luego difundida por el informe Las bases económicas para la paz. 
en 1911, aunque más de 20 años después, en 1934, sería introducida en el mundo académico, intelectual y político anglosajón bajo el título de The Theory of Economic Development: An Inquiry Into Profits, Capital, Credit, Interest, and the Business Cycle.

Desafortunadamente, tanto Esteva como Escobar, al describir en sus respectivas narrativas el naciente posicionamiento de la idea de desarrollo, no logran enfatizar ni profundizan lo suficiente el hecho de que Joseph Schumpeter y Paul Rosenstein-Rodan - pioneros teóricos de esta idea - fueron economistas vinculados con las diferentes generaciones neoclásicas continentales y, más puntualmente, con la Escuela de Viena (Newsletter, Austrian Economics, 1993) y, en esa medida, constituyeron referencias intelectuales cruciales en lo que más tarde se denominaría oficialmente como el neoliberalismo austriaco.

\section{SCHUMPETER, ROSENSTEIN-RODAN Y LAS CLAVES DEL DESARROLLO: UNA VISIÓN NEOLIBERAL HETERODOXA}

Por una parte, Schumpeter, economista perteneciente a la segunda generación de la escuela austriaca, es un icono sin discusión dentro de la evolución del naciente pensamiento y teoría neoliberales. Su influencia - sobre todo, al día de hoy - resulta determinante para las elaboraciones ulteriores no sólo de la ideología neoliberal, sino del proyecto político y, luego, del programa de políticas que desde 1947 empezarían a ser desplegados por el neoliberalismo in vitro alrededor de la Sociedad Mont-Pèlerin (Puello-Socarrás, 2008). Desde la década de 1970 y hasta la actualidad la influencia schumpeteriana se ha tornado progresivamente fundamental y sus referencias han venido siendo materializadas en distintas configuraciones concretas en la economía política global. Vale la pena recordar que la transición hacia el neoliberalismo hoy vigente - desde el régimen de acumulación conocido como Estado keynesiano de bienestar (EKB) — ha sido bautizada como Estado schumpeteriano de trabajo (EST) (véase Jessop, 1993: 17-18).

Por otra parte, Rosenstein-Rodan también estuvo vinculado con los núcleos austriacos de la teoría neoclásica pero en una generación posterior 
(cuarta) a la de Schumpeter. Durante las décadas de 1920 y 1930 Rosenstein-Rodan fue babitué del Privatseminar organizado por Mises (tercera generación de los neoliberales austriacos), iniciativa que en paralelo con otros encuentros del mismo tipo promocionados por la Fundación Rockefeller — Geistkreis ( "Círculo de la Mente», fundado por su maestro Hayek), Nationalökonomische Gesellschaft (Asociación de Economía Austríaca) y Osterreichische Institut für konjunkturforschung (Instituto Austriaco de Investigación Económica fundado por Mises y Hayek) - fueron «sin lugar a dudas la arena de entrenamiento más importante de la Escuela Austriaca» (Shulak y Unterköfler, 2011: 106).

Rosenstein-Rodan es ampliamente reconocido como el pionero de la teoría económica del desarrollo. Sin embargo, se interpreta - apresurada y erróneamente, tal como generalmente viene sucediendo con las interpretaciones convencionales que intentan descifrar el pensamiento neoliberal en general- que sus posturas son ajenas al neoliberalismo. Bajo esta suspicaz hermenéutica se insinúa que el modelo del gran impulso (big push model ideado por Rosenstein-Rodan y el cual incorpora cierto tipo de "planeación desarrollista": programas de industrialización a partir de inversiones públicas que, para el caso de los países subdesarrollados, debían ser encargadas a los gobiernos de los Estados), contradice - y niega, proponen taxativamente algunos exégetas - cualquier vínculo de filiación con las perspectivas neoliberales. ${ }^{7}$

\footnotetext{
${ }^{7}$ Escobar apenas registra la influencia de Rosenstein-Rodan aunque enfatiza las implicancias - no menos importantes, desde luego- del trabajo de Lewis. Reconoce, eso sí, la influencia de lo que denomina «las teorías clásicas y neoclásicas» en la construcción del desarrollo, pero nunca se establece explícitamente la idea de desarrollo como propiamente neoliberal; o de otro modo, consideramos que las alusiones e inferencias hechas por él y varios analistas resultan débiles e insuficientes respecto a esta crucial valoración. Lo anterior sabiendo que: «[... ] la planeación del desarrollo fue desde un comienzo la hermana melliza del desarrollo económico, lo que era evidente en 1949 cuando el Banco Mundial envió su misión a Colombia», y, al mismo tiempo: «[... A Arthur Lewis fue asesor económico del primer ministro de Ghana y subdirector general del Fondo Especial de Naciones Unidas a finales de los cincuenta. Rosenstein-Rodan fue nombrado director asistente del Departamento Económico del Banco Mundial en 1947» (resaltado y subrayado del autor) Escobar (2007: 133 y 136).
} 
No obstante, el tipo de neoliberalismo que profesa Rosenstein-Rodan, así como el asimilado por el sentido común de los contingentes heterodoxos, desde las variantes alemanas (ordoliberalismo y la escuela social de mercado) hasta las posturas austriacas (incluido Schumpeter), es un neoliberalismo de diferente cuño si se lo compara con aquel profesado por las escuelas angloamericanas, estas últimas más ortodoxas en cuanto al (neo)liberalismo de mercado. En ese sentido, el neoliberalismo ortodoxo se encuentra más estrechamente vinculado con versiones consideradas desreguladoras y dogmáticamente anti-intervencionistas del Estado en la economía, lo cual - a primera vista- reñirían con los lineamientos propuestos por el Big Push model (véase Puello-Socarrás, 2008).

Ante esta suposición, hay que subrayar — contando con el análisis de Byres (2006: 227) - , como lo hemos explicado respecto a los «disensos» en el interior de la tópica neoliberal (Puello-Socarrás, 2008, 2013), que si bien Rosenstein-Rodan efectivamente tomaba distancia de algunas perspectivas de la ortodoxia neoclásica, sus posicionamientos se contraponían casi exclusivamente a ciertas posturas adoptadas por el neoliberalismo angloamericano (sobre todo aquellas expuestas por Marshall), ${ }^{8}$ las cuales a la luz de Lewis y Rosenstein-Rodan resultaban irrelevantes "para el análisis de las economías subdesarrolladas»y, por lo tanto, «la intervención por parte del Estado era esencial». ${ }^{9} \mathrm{Ni}$ Lewis

${ }^{8}$ «[...] Rosenstein-Rodan, when he came to assess his views as one of the "pioneers in development" some forty years after the publication of his celebrated article, entitled his paper, in continuing defiance of the relevance of neoclassical economics, "Natura Facit Saltum: Analysis of the Disequilibrium Growth Process" (1984). Natura Non Facit Saltum (Nature does not Make a Jump) was the motto that Marshall placed on the frontispiece of his Principles, the first polished statement of neoclassical economics. Rosenstein-Rodan denied this."Nature" could and would make a jump; and if the jump were to be made, the state would have to intervene» (Byres, 2006: 226). Insistimos en que Byres se refiere a la teoría económica «neoclásica», denominación que en nuestra interpretación se relacionaría con las corrientes ortodoxas de las teorías neoclásicas en economía.

${ }^{9}$ Las críticas realizadas por parte de uno de los máximos referentes de la teoría del desarrollo y economista perteneciente al mainstream, el neoclásico ortodoxo Deepak Lal, de lo que él denomina el «dogma dirigista» — tanto en su versión de antaño (Big Push á la Rosenstein-Rodan) como en su nova emergente (los «nuevos dirigistas» de la nueva teoría 
ni mucho menos Rosenstein-Rodan «eran despectivos con la teoría económica neoclásica en un sentido general o último. Volverían a ella tan pronto el desarrollo estuviera asegurado» (Byres, 2006: 227) ${ }^{10}$

Esta situación, una regularidad presente a lo largo del nacimiento, evolución y consolidación del pensamiento neoliberal, es decir, la presencia de debates y diferencias entre las posturas y corrientes neoliberales (angloamericanas, austriacas y alemanas, nombrando sólo tres de sus fuentes ideológicas), más allá de si estos detalles han permanecido relativamente inadvertidos, aplica plenamente para esta discusión. No hay que olvidar que teórica y epistemológicamente los disensos entre los neoliberales angloamericanos y los neoliberales austriacos - por citar este ejemplo en particular, pues la discusión sobre el desarrollo involucra estas dos variantes en el interior del neoliberalismo- son tan profundos que a primera vista podrían parecer horizontes antípodas. Ciertamente, a nivel epistemológico lo son ( $c f r$. Puello-Socarrás, 2008: 56-70).

Pero, tal y como lo hemos explicado en otras oportunidades (PuelloSocarrás, 2008, 2011, 2013), cuando las discusiones del neoliberalismo salen del terreno de la abstracta teoría (económica) y entran en el campo estratégico y concreto del proyecto político (paradigmático), las diversas posturas, escuelas y posicionamientos neoliberales en principio opuestos convergen al unísono alrededor de un consenso crucial y confluyen en torno - al decir del propio Hayek - a una unidad ideológica

del desarrollo: Gerald Meier y Dani Rodrik, entre otros) - es un buen ejemplo para desatar algunas confusiones. Las críticas de Lal (2012) presentadas con el objetivo de defender la vigencia para el siglo xxi del enfoque contenido en el primer Consenso de Washington (de 1989) - recordemos, un programa de politicas-, están próximas a una perspectiva leséferista y, por lo tanto, una visión neoliberal ortodoxa del desarrollo (aunque este debate se mantiene al nivel de la acción instrumental, de las políticas). No supone, pues, ninguna controversia a nivel del paradigma del desarrollo neoliberal vis-a-vis las versiones heterodoxas de los nuevos dirigistas. Es más, varias de sus conclusiones en defensa de la ortodoxia neoliberal recurren a las perspectivas del neoliberalismo heterodoxo de Hayek y Mises, entre otros.

${ }^{10}$ Trasladando nuestra hermenéutica al lenguaje que utiliza Byres, este autor estaría refiriéndose a las corrientes ortodoxas paulatinamente dominantes dentro del neoliberalismo naciente de la época. 
fundamental (Puello-Socarrás, 2008: 70-78) que unifica consistentemente los criterios del neoliberalismo in extenso sin contradicciones. ${ }^{11}$ Esta situación parecería estar planteada - aún entrelíneas - por Escobar (2007) respecto a Schumpeter sin llegar todavía a reflexionar con mayor énfasis y profundidad sobre el carácter eminentemente neoliberal de las posiciones schumpeterianas sobre el desarrollo/subdesarrollo:

La teoría de Schumpeter debió haberse considerado oportuna para las preocupaciones de los primeros economistas del desarrollo. Schumpeter no sólo se interesaba en los pequeños cambios de la vida económica, sino precisamente en los cambios revolucionarios considerados como necesarios por los economistas en las teorías del «gran empujón» y el «despegue». Sin embargo, adherir al marco schumpeteriano habría significado tomar en serio algunos aspectos que habrían planteado problemas incómodos a la mayoría de los economistas del periodo: por ejemplo, el hecho de que para Schumpeter el crecimiento no significara por sí mismo desarrollo, sino simples «cambios en los datos»; o que «el estado económico de un pueblo no proviene simplemente de sus condiciones económicas precedentes, sino de su situación anterior en su totalidad» (Schumpeter, 1934:58). ¿Cómo podrían traducirse sus opiniones en modelos y esquemas de planeación razonables?

\title{
Enseguida complementa:
}

Otras influencias desempeñaron un papel en la exclusión de las ideas de Schumpeter. Por ejemplo, el hecho de que la economía del desarrollo fuera casi exclusivamente asunto de las instituciones académicas angloamericanas,

\begin{abstract}
${ }^{11}$ Por ello, antes que concebir al neoliberalismo como una comunidad epistémica hay que considerarlo una comunidad ideológica, en la cual se registran diferentes disensos de orden teórico, epistemológico, de cursos de acción al nivel de las políticas (policies), etcétera, en el interior del neoliberalismo sin que ello obstruya que, al nivel de los principios generales y abstractos (paradigma), exista una unidad ideológica común y fundamental. Por ejemplo, Hartwell, ex presidente de la Sociedad Mont-Pèlerin y autor de A History of Mont Pèlerin Society (1995) «(...) also notes MPS members, if united on the idea of freedom, have had to deal with sharp internal differences over means. Substantive debates within the society have ranged over social security, public schools, economic development...» (subrayado del autor) (Peterson, 1996: 532-533).
\end{abstract}


para las cuales el pensamiento sistémico de Schumpeter — proveniente de una tradición intelectual distinta - resultaba algo extraño; y el hecho de que su teoría no se prestara fácilmente para el tipo de elaboraciones matemáticas a las cuales se iban aficionando algunos economistas del desarrollo... [resaltado y subrayado del autor] (Escobar, 2007: 138).

La aludida «exclusión» de las ideas de Schumpeter en relación con el debate sobre el desarrollo naufraga analíticamente cuando Escobar ubica a Schumpeter en una «tradición distinta», sugiriendo una suerte de exasperación en las fronteras propias de la tradición neoliberal. Es cierto que las ideas schumpeterianas en ese momento adolecían de un privilegio epistémico superior del cual disfrutaban las tradiciones neoclásicas ortodoxas, es decir, las escuelas angloamericanas y sus instituciones académicas. Por ello, a nivel teórico las ideas heterodoxas de Schumpeter, «alejadas» de la ortodoxia neoliberal y aparentemente en una posición «crítica» frente a las formulaciones específicas del mainstream, fueron excluidas de los debates centrales sobre el desarrollo (en especial, las controversias más «técnicas"). Pero este hecho no se explica extramuros al neoliberalismo. Por el contrario, el análisis debe ubicarse en el interior de la tópica neoliberal, reflexión que en este caso brilla por su ausencia.

Un cuadro análogo se presenta a lo largo de la trayectoria intelectual de Rosenstein-Rodan en relación con el mismo tema de la estilización matemática, la cual para algunos comentadores es infrecuente e insuficiente en su teorización. Meier, y especialmente Krugman, han señalado al respecto que la falta de persuasión de la («vieja») teoría económica del desarrollo de Rosenstein-Rodan se explicaría debido a que «sus ideas no estaban formalizadas en matemáticas» (citado por Lal, 2012: 495). ${ }^{12}$ Aquí debe recordarse que una de las críticas históricas

${ }^{12}$ En vista de que Lal no aporta ninguna información precisa sobre este particular, sería válido pensar que la falta de "persuasión» de las teorías del desarrollo de Schumpeter y Rosentein-Rodan por sus aparentes déficits en la «estilización matemática»se circunscribirían a los círculos intelectuales de economistas académicos del mainstream de 
interpuestas por las versiones ortodoxas hacia sus contrapartes heterodoxas en los debates epistemológicos que se han desatado en el interior del neoliberalismo es precisamente la incapacidad de los heterodoxos en traducir sus propuestas teóricas al lenguaje matemático y lograr así la estilización lógico-formal de las explicaciones económicas en «modelos». Inversamente, las corrientes menos convencionales especialmente las austriacas - han denunciado tal pretensión ortodoxa como un «abuso de la razón» y un cientismo en la construcción de la ciencia económica (véase Hayek, 1952).

Más allá de esta polémica puntual, una situación similar ocurre en relación con la interpretación de otros tópicos del desarrollo en la obra de Rosenstein-Rodan en particular, y del neoliberalismo heterodoxo en general.

Recientemente se ha venido activando una confusión teórica abstracta pero de importantes consecuencias en términos políticos reales en relación con la acción del Estado y el neoliberalismo. La tesis que prevalece sostiene la incompatibilidad insalvable entre Estado y mercado sin notar que la acción y presencia estatales son y han sido una necesidad (permanente y contingente) para el capitalismo histórico incluyendo, por supuesto, su fase neoliberal.

Esta interpretación soslaya que si bien es cierto que las corrientes ortodoxas del neoliberalismo se han caracterizado por profesar cierta aversión «anti-estatista» (anti-intervencionista, en realidad), esto no significa que sean inconscientes de que la acción del Estado (en su versión des-regulativa, por ejemplo) sea considerada indispensable para el funcionamiento del libre mercado. En el caso de las corrientes heterodoxas neoliberales, éstas han reclamado más explícitamente la construcción, al mismo tiempo, de una sociedad (no sólo una economía) de mercado libre y un Estado fuerte y activo a partir de «intervenciones selectivas», es decir, regulando los mercados. Esta modalidad de acción

la época. De lo contrario, no se podría explicar la ascendencia, por ejemplo, en el caso de Rosenstein-Rodan como economista del desarrollo en otros campos profesionales, como aquí se ha reseñado, o la que mantiene al día de hoy Schumpeter. 
estatal en particular se aparta celosamente de cualquier pretensión intervencionista (a la Keynes) y está taxativamente disociada de la planificación centralizada (vinculada con los socialismos llamados «reales»).

En este sentido, inveteradamente la propuesta del neoliberalismo heterodoxo ha sostenido que:

[... ] Donde el mercado fuera efectivamente caracterizado como «competencia perfecta» el Estado podría confinar ampliamente su atención a la preparación de las condiciones de un marco legal (como en el caso de la agricultura). En la industria, donde los mercados estaban caracterizados por la «competencia imperfecta», la estrategia sería minimizar todos los sectores de la economía... mediante «intervenciones selectivas del Estado en la economía» [resaltado y subrayado del autor] (Rieter y Schmolz, 1933: 100).

No sobra traer a colación que precisamente el primer experimento neoliberal en concreto, mucho antes de establecer su hegemonía global a partir de 1970, estuvo protagonizado por la reconstrucción de la $\mathrm{Re}$ pública Alemana Federal. Este primer experimento del neoliberalismo in vivo se forjó en torno a la sentencia Freie Wirtschaft, starker Staat ("Economía libre, Estado fuerte"), idea-guía concebida y luego cuidadosamente puesta en práctica por las escuelas neoliberales alemanas, del ordoliberalismo a la economía social de mercado, es decir, corrientes del neoliberalismo heterodoxo y que estaban no sólo personificadas, sino directamente personalizadas por miembros alemanes de la Sociedad Mont-Pèlerin (véase Puello-Socarrás, 2008: 32 y 34-42).

Un testigo excepcional y conocedor de este debate, gracias a su proximidad histórica, personal e ideológica con las posturas neoliberales heterodoxas, «críticas» del neoliberalismo ortodoxo, como Karl Polanyi, clarificó varios detalles de esta polémica en 1944, es decir, hace más de seis décadas, en La gran transformación, al insistir:

El liberalismo económico, hablando con propiedad, es el principio director de una sociedad en la cual la industria está fundada sobre la institución de un 
mercado autorregulador. Es cierto que una vez que este sistema está casi desarrollado, se necesitan menos intervenciones de un determinado tipo; sin embargo, esto no quiere decir, ni mucho menos, que sistema de mercado e intervención sean términos que se excluyan mutuamente ya que, durante el tiempo que este sistema no está en funcionamiento, los representantes de la economía liberal deben pedir - y no dudarán en hacerlo- que intervenga el Estado para establecerlo y, una vez establecido, para mantenerlo. Los representantes de la economía liberal pueden, pues, sin incoherencia por su parte, pedir al Estado que utilice la fuerza de la ley e incluso reclamar el uso de la violencia, de la guerra civil, para instaurar las condiciones previas a un mercado autorregulado [...] incluso los defensores más radicales del liberalismo económico, no han podido evitar la regla que hace del laissez-faire algo inaplicable en las condiciones existentes en una industria desarrollada [...] los liberales extremistas tuvieron que solicitar del Estado todo tipo de intervenciones, con el fin de asegurar las condiciones necesarias para el funcionamiento de un mercado autorregulador, enfrentándose a los convenios monopolistas. El librecambio y la concurrencia, para poder funcionar, exigieron ellos mismos intervención [resaltado y subrayado del autor] (Polanyi, 1944: 276).

Retomando Rosenstein-Rodan, su pensamiento, y especialmente sus actuaciones, fueron consecuentes con las combinatorias que antes ilustramos. Más puntualmente: la necesidad de regulación estatal (un tipo de acción/intervención estatal y situación, insistimos, que no debe ser confundida ni con el intervencionismo estatal ni con la planificación estatal centralizada). ${ }^{13}$

\begin{abstract}
${ }^{13}$ Por la misma época se sostuvieron posiciones que defendían lo que se ha denominado el estatismo del Tercer Mundo, como en el caso de Gunnar Myrdal para quien «las economías del Tercer Mundo estaban plagadas por "círculos viciosos que sólo pueden romperse con una planeación estatal de gran escala y la intervención estatal" " (Myrdal citado por Babb, 2009: 50), y que seguramente generaron este tipo de confusiones. Sobre las diferencias entre desregulación, regulación, intervencionismo y planificación centralizada en tanto diferentes versiones de la acción estatal, véase Puello-Socarrás (2013a; 2013b). Paradójicamente, uno de los teóricos del desarrollo más influyentes, Bauer, miembro de la Sociedad MontPèlerin y fiel representante de los círculos neoliberales ortodoxos, calificó a las posiciones de Myrdal como la «nueva ortodoxia del desarrollo económico» (véase Bauer, 1958).
\end{abstract}


En este caso, la idea de desarrollo de Rosenstein-Rodan no se resringe a un asunto de «economía pura» ni de «pura economía», perspectiva común presente en las corrientes del mainstream que profesan el perfil ortodoxo y que interpretan los problemas como si fueran simplemente cuestiones económicas «técnicas» — por ejemplo, Rostow (1961), quien pretende justificar la cuestión del desarrollo ocultando el núcleo ideológico que lleva consigo su visión política-. Debe subrayarse que el desarrollo en la versión heterodoxa en Rosenstein-Rodan significaba ante todo un problema político de la economía y, para ese momento histórico, de la mayor trascendencia para el capitalismo.

Desde sus días como director del Chatham House, ${ }^{14}$ entre 1941 y 1943, Rosenstein-Rodan se propuso describir «las características comunes al subdesarrollo». Así, primero se dedicó al estudio de los «Problemas de la industrialización en el este y sureste de Europa» (artículo publicado en Economic Journal en 1943) y, luego, al «Desarrollo internacional de las áreas económicamente atrasadas» (publicado en Foreign Affaires en 1944), documento que se ocupa, además de Europa, de zonas como el Caribe, África, el Lejano y el Medio Oriente con el fin de enfatizar que «el subdesarrollo se [había] convertido en un problema tanto político como moral» advirtiendo que «la gente preferirá morir luchando [en el momento en el cual] no vean perspectiva alguna de mejor vida». Tal y como lo recuerda Arndt, coequipero de Rosens tein-Rodan en el mencionado ensayo de 1944, el desarrollo de las áreas económicamente atrasadas del mundo sería «la tarea más importante a la que nos enfrentamos para la consecución de la paz». Con ese objetivo, resultaba primordial y urgente proveer amplias facilidades para la formación laboral (en agricultura, especialmente) — «de lejos, el problema más importante en las áreas atrasadas»- mediante esquemas gubernamentales en vista de que, por razones prácticas, alejadas de cualquier dogmática (ortodoxa), tal situación sería insuperable mediante

${ }^{14}$ Instituto Real de Estudios Internacionales, el equivalente británico del Council on Foreign Relations estadounidense. 
inversiones privadas (en tanto no eran «atractivas»), pero ciertamente posible si se imaginaban como una «buena inversión para el Estado» (Rosenstein-Rodan citado por Arndt, 1972: 28-29).

Una perspectiva equivalente era promovida para el caso de la industrialización de los países subdesarrollados. En los términos de Rosenstein-Rodan, este proceso significaba grandes ventajas, si y sólo si era conducido «con la ayuda de inversiones extranjeras de gran escala» (Rosenstein-Rodan citado por Arndt, 1972: 29) lo cual, evidentemente, implicaría que las «ayudas» para superar el subdesarrollo deberían ser canalizadas a través del Estado — no a través de instancias privadas, insistimos - y, prioritariamente, en la forma de endeudamiento público. Se trataba de una línea de acción que progresivamente conquistaba un consenso generalizado dentro del pensamiento de esa época, precisamente en los círculos donde se originaban las reflexiones sobre el desarrollo.

En 1939, Eugene Staley, desde el Council on Foreign Relations (el equivalente usamericano del Instituto Real de Estudios Internacionales conducido por Rosenstein-Rodan), ya había persuadido sobre la necesidad de crear «un banco de inversión internacional de largo plazo para financiar los servicios públicos mundiales... [y] transferir el conocimiento y sus aplicaciones industriales internacionalmente» (Staley citado por Arndt, 1972: 26). Un par de años más tarde, en la misma publicación donde aparecía el artículo seminal de Wilfred Benson, se anotaba paralelamente: «[... ] el hecho es que el préstamo internacional ha sido uno de los motores más poderosos del progreso económico a través del mundo, y esa es una inmensa tarea que nos queda por realizar...» (Durvin citado por Arndt, 1972: 27).

Es imposible soslayar las síntesis e implicaciones de estos acontecimientos en su sentido económico-político y en su significación (neo) colonial; en especial si se advierte la estrecha relación existente entre las orientaciones imperialistas hacia la exportación de capitales (desde el centro hacia las periferias) y los imperativos que supone el endeudamiento externo (es decir, la deuda externa como instrumento de dominación 
política y económica, y mecanismo de transferencia de riquezas creadas por el trabajo a favor del capital) vis-a-vis la profundización de las dinámicas, las lógicas y, sobre todo, las contradicciones del (sub)desarrollo en el capitalismo tardío durante el siglo xx. Esta tendencia se profundiza precisamente con la configuración originalmente neoliberal de la idea de desarrollo y sus prolongaciones neo-imperialistas actuales en el nuevo milenio (véase Harvey, 2004).

\section{La idea de desarrollo y la Sociedad Mont-Pèlerin}

El desarrollo, aunque especialmente el subdesarrollo, son objeto en adelante de reflexiones sistemáticas y permanentes en las agendas neoliberales desplegadas desde la fundación de la Sociedad Mont-Pèlerin en 1947. Y si bien Rosenstein-Rodan o Schumpeter (fallecido en 1950) participaron oficialmente en las reuniones que se propiciaron en este cónclave neoliberal; sus aportes fueron ( $y$ siguen siendo) fundamentales para la organización de ideas y acciones en la arquitectura del proyecto político y las trayectorias efectivas del neoliberalismo. ${ }^{15}$

$\mathrm{Al}$ principio el tema del desarrollo en este marco estuvo relativamente subordinado a otras prioridades (Plehwe, 2009: 238-279), especialmente aquellas relacionadas con la coyuntura política internacional de los años de posguerra. Empero, este tópico se convierte poco a poco en una clave discursiva crucial con la intensificación de la guerra fría.

\footnotetext{
${ }^{15}$ No se ha valorado suficientemente qué es la Sociedad Mont-Pèlerin en su conjunto (pensamiento colectivo) - y no sólo sus miembros en singular- quien será la plataforma clave para la restauración y posicionamiento de la teoría económica del desarrollo en su sentido inaugural/original en función de la hegemonía neoliberal a partir de la década de 1970. Omitiendo vincularlos con la Sociedad Mont-Pèlerin, Babb (2009: 51) anotaः «[... ] Yet development economics was never hegemonic. The rise of the subfield was accompanied, at all times, by strong criticism from neoclassical and others who objected to its methods and conclusions. One of the most infamous critics was P. T. Bauer, an economist at the London School of Economics, but there were many others: Jacob Viner, Harry Johnson, Gottfried Haberler, and Hebert Frenkel are some prominent examples».
} 


\section{Cuadro 1}

Reuniones de SMP referidas al Subdesarrollo (1951-1964) (continúa)

\begin{tabular}{|c|c|c|c|}
\hline Reunión & Fecha & Lugar & Mesa debate / Tópicos / Lectura \\
\hline $4^{\mathrm{a}}$ & $\begin{array}{l}\text { Septiem- } \\
\text { bre 4-16 } \\
(1951)\end{array}$ & $\begin{array}{l}\text { Beauvallon } \\
\text { (Francia) }\end{array}$ & $\begin{array}{l}\text { Liberalism and the Underdeveloped Countries } \\
\text { Participantes: W.E. Rappard (moderador), F. Benham., } \\
\text { S.H. Frankel., L. Baudin, H. Hazlitt., J. Jewkes, W. } \\
\text { Röpke., P.T. Bauer. }\end{array}$ \\
\hline $7^{\mathrm{a}}$ & \begin{tabular}{l|} 
Agosto 29 \\
- Septiem- \\
bre 3 \\
$(1956)$
\end{tabular} & $\begin{array}{l}\text { Berlín } \\
\text { (Alemania) }\end{array}$ & $\begin{array}{l}\text { "Soviet Expansion in the Under-Developed Countries" } \\
\text { por L. Baudin } \\
\text { Participantes: L. von Mises (moderador), B.F. Menéndez, } \\
\text { T.J.B. Hoff, F. Böhm, F.A. Harper, B. Pfister, J.V. Van Sic- } \\
\text { kle, E. Menéndez, F.A. Lutz, S. Rydenfelt. }\end{array}$ \\
\hline $9^{a}$ & $\begin{array}{l}\text { Septiem- } \\
\text { bre 8-13 } \\
(1958)\end{array}$ & $\begin{array}{l}\text { Princeton, } \\
\text { New Yersey } \\
\text { (EE.UU.) }\end{array}$ & $\begin{array}{l}\text { Under-Developed Countries } \\
\text { "Regulated Wages in Under-Developed Countries" por } \\
\text { P.T. Bauer } \\
\text { Participantes: A.A. Shenfield (moderador), D.M. Wright, } \\
\text { G.R. Velasco, N. Kiuchi, S.H. Frankel, L. von Mises, E. } \\
\text { Gudin, R. Ferrero. }\end{array}$ \\
\hline $11^{\mathrm{a}}$ & $\begin{array}{l}\text { Septiem- } \\
\text { bre 5-10 } \\
(1960)\end{array}$ & $\begin{array}{l}\text { Kassel } \\
\text { (Alemania) }\end{array}$ & $\begin{array}{l}\text { Under-Developed Countries } \\
\text { “Whom Should We Aid?" por P.T. Bauer } \\
\text { "Die Schwerpunkte der wirtschaftlichen Strategie des } \\
\text { Ostens bei der Einflussnahme auf die Entwicklungslän- } \\
\frac{\text { der" por W. Förster. }}{\text { "Growth Theories - Old and New" por J. Van Sickle }} \\
\text { "Under-Developed Countries" por G.A. Duncan } \\
\text { "The Goal of Economic Development" por D.C. Renooij } \\
\text { "Le problème de l'aide aux peuples sous-développés" } \\
\text { por L. Rougier } \\
\text { Participantes: D. Villey (moderador), H.O. Wesemann, W. } \\
\text { Röpke, A. Rüstow, M. Thurn, W. Förster, E. von Kueh- } \\
\text { nelt-Leddihn, A. Fredborg, M.A. Heilperin, A. Navarro V., } \\
\text { J. Davenport, G.J. Stigler, N. Zuloaga. }\end{array}$ \\
\hline $12^{\mathrm{a}}$ & $\begin{array}{l}\text { Septiem- } \\
\text { bre 3-9 } \\
(1961)\end{array}$ & $\begin{array}{l}\text { Turín } \\
\text { (Italia) }\end{array}$ & $\begin{array}{l}\text { The Western Countries and the Under-Developed World } \\
\text { "Western Countries and Under-Developed Countries" } \\
\text { por K. Brandt } \\
\text { "Le monde occidental et ses pays sous-développés" por } \\
\text { G. Leduc } \\
\text { "A Theory of Economic Development" por G.U. Papi } \\
\text { "Les Pays Occidentaux et les régions sous-dévéloppées. } \\
\text { Résumé d'une intervention" por J. Van Offelen } \\
\text { Participantes: J. Davenport y L. von Mises (no confirma- } \\
\text { dos). B. Pfister, A. Rüstow, D. Villey. } \\
\text { Communism in Italy, France and South America }\end{array}$ \\
\hline
\end{tabular}




\section{Cuadro 1}

Reuniones de SMP referidas al Subdesarrollo (1951-1964) (concluye)

\begin{tabular}{|c|c|c|c|}
\hline Reunión & Fecha & Lugar & Mesa debate / Tópicos / Lectura \\
\hline & & & $\begin{array}{l}\text { "On the Threat of Communism in Latin America" por S. } \\
\text { de Madariaga } \\
\text { "Le communisme en France" por H. Hornbostel } \\
\text { "Religion and Communism in Latin America" por E. von } \\
\text { Kuehnelt-Leddihn } \\
\text { "Communism in South America" por D.M. Wright } \\
\text { "Communism in Latin America from an Argentine Point } \\
\text { of View and with Reference to the Notion of Underdeve- } \\
\text { loped Countries" por C.A. Benegas. }\end{array}$ \\
\hline $14^{\mathrm{a}}$ & $\begin{array}{l}\text { Septiem- } \\
\text { bre } 7-12 \\
(1964)\end{array}$ & $\begin{array}{l}\text { Semmering } \\
\text { (Austria) }\end{array}$ & $\begin{array}{l}\text { Freedom and Order in the Under-Developed Countries } \\
\text { and the Problem of Aid } \\
\text { "Freedom and Order and Aid to Underdeveloped Coun- } \\
\text { tries" por S.H. Frankel } \\
\text { "Freedom and Order in the Underdeveloped Countries } \\
\text { and the Problem of Aid" por N. Kiuchi. } \\
\text { "Freedom and Order in the Underdeveloped Countries } \\
\text { and the Problem of Foreign Aid" por B.R. Shenoy } \\
\text { "Le problème de l'aide au développement et le cas de } \\
\text { l'Algérie" por G. Leduc } \\
\text { "Suggestions on Economic Cooperation with developing } \\
\text { Countries - Redeemable Shares as a Principal Step to- } \\
\text { ward the Facilitation of Private Investment" por S. Na- } \\
\text { kayama. }\end{array}$ \\
\hline
\end{tabular}

Fuente: Autor con base en Mont-Perèlin Society (2004).

Dentro de esta articulación, el papel que jugaría el (libre) comercio internacional, una de las tres grandes preocupaciones dentro de la Sociedad Mont-Pèlerin (los otros dos eran el carácter del Estado y la influencia del socialismo), fue discutido amplia y sistemáticamente en varias conferencias neoliberales con la particularidad de que era tratado en relación con los países en subdesarrollo desde los tempranos años de la década de los cincuenta (véase cuadro 1 ).

En una de las más famosas conferencias de la Sociedad, en la cual precisamente debuta el tema, realizada en Beauvallon, Francia, en 1951, existió un panel titulado: «Liberalismo y los países subdesarrollados». 
El objetivo primordial de esta convocatoria - como todas estas aventuras intelectuales - fue provocar un marco ideológico elemental y, luego, referentes para la acción práctica que resolvieran el «acertijo» del subdesarrollo bajo una visión neoliberal $y$, por consiguiente, una fórmula que cuidadosamente se mantuviera distante técnica y, sobre todo, políticamente de las posturas keynesianas, estructuralistas o socialistas que venían paralelamente aireando este debate.

Desde un principio, el neoliberalismo convino en que:

[... el principal camino hacia el progreso económico para los países subdesarrollados [proponía Benham en 1951] está en incrementar su producto por trabajador en la agricultura y especializarse en producir para exportar esos bienes y servicios en los cuales ellos tengan ventajas comparativas [...] (citado por Plehwe, 2009: 247).

Tiempo después, durante las discusiones de la $9^{a}$ reunión de la Sociedad Mont-Pèlerin, realizadas en Princeton, Nueva Jersey, Estados Unidos, en septiembre de 1958, en las cuales se discutía el tema del desarrollo en el panel "Los países subdesarrollados", teniendo como referencia base dos escritos enviados con antelación por Bauer ( Regulación de salarios en los países subdesarrollados»y, especialmente, «La nueva ortodoxia del desarrollo económico»), John Davenport ampliaba los criterios antes postulados por Behman, aclarando además que:

[... I do not think we should delude ourselves that just trade and foreign investment will do this whole job. The real advance has to come from the socalled «underdevelopment countries» themselves; trade and foreign investment are marginal to what they can do. And perhaps the greatest task is to persuade them that they can develop normally and naturally by sticking to well-tested economic principles - the principle of sound money, for instance, and the principle of limited versus unlimited government. For what they need most is not gigantic Five-Year or Ten-Year Plans, but rather, renewed faith in the efficacy of the market economy and a system which allows individuals to go to work, and so to contribute to the general welfare (Davenport, 1958). 
La respuesta neoliberal desde Sociedad Mont-Pèlerin proponía paradigmáticamente que la idea de desarrollo debía traducirse en una estrategia económica basada en la especialización de la producción tradicional agrícola dirigida «hacia afuera» (exportación) y, por lo tanto, orientada hacia el mercado (es decir, dirigida al libre comercio internacional), manteniendo subsidiariamente el presupuesto de la estabilización macroeconómica (elevando el principio monetario de la «moneda sana» vía mercado «limitando» - no eliminando - la acción gubernamental). Por supuesto, se trata de una visión que riñe en casi todos los aspectos frente a la política de industrialización por sustitución de importaciones y el desarrollo nacional «hacia adentro» en boga en los proyectos capitalistas de esos años. Además, esta postura resulta completamente antípoda si se la compara con los detalles económico-políticos presentes en los regímenes socialistas de planificación centralizada y también con el modelo anfibio del estatismo del Tercer Mundo (Myrdal) el cual pretendía combinar selectivamente intervencionismo y planeación estatales.

¿Qué implicaciones conllevaría lo anterior en términos de la significación económico-política del desarrollo y complementariamente en relación con el componente puntualmente colonial que se le inculcaría al neoliberalismo? Primero: la traducción del paradigma neoliberal en la estrategia de desarrollo sugiere:

[...] la concentración recomendada en el sector primario (especialización de las exportaciones en áreas competitivas) [... [ [la cual] no podría desafiar la prevaleciente división global del trabajo estando así en línea con los intereses (conservadores) de los países desarrollados aún con el control de los territorios coloniales (asegurando un mejor y continuado acceso a los insumos primarios y evitando potencialmente nueva competencia para sus propias exportaciones industriales a las regiones) (Plehwe, 2009: 247-248).

En segundo término — subraya una vez más Plehwe (2009: 248) este tipo de argumentaciones estaban plenamente arraigadas en los 
«estereotipos típicos de la antropología victoriana prevalecientes en el discurso comparativo del evolucionismo del siglo XIX», es decir, discursos coloniales de la época colonialista (en este caso británica; recordemos las alusiones de Truman sobre los «administradores coloniales» cuando se refería ambigua y selectivamente al «desarrollo») y que marcan un tipo de continuidad que se materializa a través de un aggiornamento espacio-temporal de tal cosmovisión ideológica y política.

Bien lo señala Sachs cuando advierte que el desarrollo como idea pretende actualizar el colonialismo anterior definiendo ahora el mundo como arena económica. Este cambio pretende fetichizar (extrañar, ocultar) su núcleo colonialista, ya que en su versión original éste basaba su dominación en: 1) una «obligación cultural» originada por su supuesta vocación civilizadora (elevar a un nivel mayor de civilización: el doble mandato Lord Lugard), presentando 2) a los colonialistas como amos y no planificadores, es decir, bajo la figura «técnica» con la que actualmente aparecen:

[...] Los colonialistas llegaron a mandar a los nativos como amos, y no como planificadores a impulsar la espiral de la oferta y la demanda. Los imperios coloniales eran percibidos como espacios políticos y morales en los que las relaciones de autoridad daban el tono, no como pasos económicos articulados en torno a las relaciones comerciales (Sachs, 1996:3).

A diferencia de la doctrina Truman que lo encubría relativamente, la discursividad sobre el desarrollo mantenida por el neoliberalismo en la Sociedad Mont-Pèlerin es bastante explícita respecto a sus objetivos ideológicos y políticos. Advierte, sin ningún tipo de cortapisas, que «el progreso sólo podía lograrse basándose en la economía de mercado», axioma que justamente justificó los esfuerzos de la naciente Sociedad Mont-Pèlerin, casual o causalmente en el mismo año en que se pronunciaba la doctrina sobre el desarrollo, y bajo las mismas pretensiones de «ayudar» a los países «en desarrollo» y los considerados «subdesarrollados» vía la dinámica del mercado (un principio fuera de toda discusión) 
e instrumentalizada con la intervención estatal necesaria y contingente mediante - según sea el caso- la planificación. ${ }^{16}$

Este acontecimiento, por otro lado, está bastante lejos de proponer la idea de desarrollo, como lo ha sugerido Sachs (1999): «un concepto lleno de vacío», incluso, «sin contenido» y ambiguo.

Sin ir en detrimento de que efectivamente el desarrollo como idea, concepto, discurso o narrativa ha cumplido una función en tanto praxis (tal vez el espacio por antonomasia de la batalla de ideas en la hegemonía económico-política durante el siglo $\mathrm{xx}$ ) hay que consignar también que, desde un principio, es decir, en sus orígenes, existió claridad respecto a los principios abstractos y generales que guiarían estratégicamente (en el largo plazo) esta idea-fuerza clave dentro del proyecto político del neoliberalismo. El paradigma de desarrollo — al mismo tiempo, el del subdesarrollo - ha trascendido a lo largo del tiempo.

Las traducciones de la estrategia (económica) convencional del desarrollo durante la hegemonía neoliberal global in vivo desde la década de 1970 y hasta la actualidad permiten confirmar este hecho. El núcleo del desarrollo ha venido materializándose sistemática y consistentemente en las fórmulas de gobierno, formas de acción institucional y programas de políticas neoliberales (por ejemplo, el Consenso de Washington, ya sea en su versión original de 1989 o en sus diferentes versiones ulteriores), tal y como lo justifican y confirman sus propios defensores:

[... D Durante los 80s y a principios de los 90s hubo una marcada transformación en el pensamiento económico en América Latina. La visión dominante basada en un pesado intervencionismo de Estado, orientación hacia adentro,

${ }^{16}$ En el prefacio de los archivos de la Socieda Mont-Pèlerin se anota taxativamente: «Progress can only be made by relying on the market economy [...] The world needs a competitive system for two reasons. First, the Western economies benefitting by this system still have to eliminate remaining aspects of poverty by new social laws and through diminishing environmental pollution. These efforts are expensive and require an increase of the productivity. On the other hand, the free market economy remains necessary in order to aid the developing countries which preferably make an appeal to our knowhow and equipment» (resaltado y subrayado del autor) (Mont-Pèlerin Society, 2005: 4). 
e inobservancia de los balances macroeconómicos lentamente dio paso a un nuevo paradigma basado en la competencia, la apertura y orientación hacia el mercado [... E El wc es una versión latina de lo que, de hecho, se había convertido el consenso a nivel mundial en los 90 . Tenía en común con la versión internacional la convicción de que la prosperidad económica sólo podría ser obtenida mediante la sujeción al poder del mercado [... ] El nuevo paradigma animó el libre juego de las fuerzas de mercado para coordinar a través de las señales de los precios [...] decisiones descentralizadas de empresas e individuos, y así permitía una asignación eficiente de recursos y fomentaba un emprendedorismo creativo [subrayado del autor] (Birdsall, De la Torre y Valencia, 2011:6).

La idea de desarrollo/subdesarrollo no sólo se identificaría con una cuestión abstracta estratégica al nivel político-ideológico y, si se quiere, simplemente existe a un nivel paradigmático actualizada hoy en el terreno de la economía pura.

Como muestran casos de estudio puntuales, hay evidencia actual sobre políticas concretas que en el pasado reportaron algún tipo de productividad emanada de la funcionalidad política que representa la necesidad de una relación colonial para el capitalismo y que han sido tácticamente «trasladadas» (en el tiempo) y «transferidas» (en el espacio) hacia otros contextos. El caso contemporáneo de Argentina durante la década de 1990 con la instalación de políticas económicas neoliberales, específicamente: el régimen de la convertibilidad - de impronta colonialista-, ilustra ampliamente este punto (véase Plehwe, 2011).

A través de lo anterior, el neoliberalismo ha logrado consolidar gran parte de la dependencia y subordinación neocoloniales en la reproducción y acumulación asimétricas necesarias para su proyecto entre centro(s) y periferia(s), o - como más recientemente se ha venido convocando- entre el Norte y el Sur globales (geografías espacio-temporales epistémicas y concretas del capital).

En esta perspectiva in vitro, las tesis sobre colonialismo externo (más cercano al imperialismo y nuevo imperialismo) e interno son ple- 
namente actuales y válidas. Refuerzan además, en ambos niveles, las lógicas y las contradicciones exacerbadas del capitalismo en términos de dominación, explotación, opresión y alienación de la fase actual, es decir, neoliberal.

\section{LIMINAR}

Un reciente y sugestivo escrito de Arturo Escobar (2014:202) convoca transitar definitivamente del desarrollo al postdesarrollo en América Latina y el Caribe. Allí anima a continuar desatando los cambios de época que últimamente viene observando la región. Esta nueva tendencia histórica - complementa al respecto Coraggio (2014: 167) — no solamente ha venido cuestionando «las políticas de los gobiernos neoliberales, o la relación de dependencia de la periferia, o el sistema capitalista, sino el sistema civilizatorio de la modernidad eurocéntrica, que en el siglo xx se constituyó como proyecto desarrollista».

Sin embargo, la caracterización sobre una posible era postliberal (y post-desarrollista), es decir, la transformación del liberalismo y el desarrollo como nuevo proyecto basado en un espacio/tiempo que «no es tuviese por completo determinad[o] por los constructos de la economía, el individuo, la racionalidad instrumental, la propiedad privada y demás factores que caracterizan al liberalismo y a la Modernidad» (Escobar, 2014: 201) podría resultar incompleta, anacrónica y hasta obsoleta incluso inane, políticamente hablando-. Perspectivas como la descrita en Escobar corren el riesgo de considerar sólo una de las múltiples facetas del (neo)liberalismo ( $y$, en ese sentido, de la idea de desarrollo) en su existencia contemporánea. De esta manera, otros aspectos del neoliberalismo, los cuales en el recambio y renovación neoliberales continúan consolidando la idea de desarrollo y reconfigurando sus prácticas, resultan inadvertidos. En el mejor de los casos, aún se mantienen entre paréntesis o simplemente se ocultan. 
La caracterización acrítica del «regreso del Estado» y la supuesta incompatibilidad entre el Estado y el mercado, por ejemplo, en dispositivos que constituyen «nuevas» formas de actuación institucional (gobernanza) y de políticas públicas (alianzas público-privadas) incluyendo orientaciones recurrentes en las nuevas políticas «sociales» (transferencias monetarias condicionadas) (véase Puello-Socarrás y Gunturiz, 2013); el (nuevo) referente emprendedor y el emprendedurismo (entrepreunership) trayendo a colación algunos ejemplos cruciales, son varios aspectos que aún no son reflexionados teóricamente ni tratados políticamente en forma sistemática.

Paradójicamente, si no se incorporan análisis que en forma más amplia reconozcan, introduzcan y articulen las novedades más sustanciales acerca de las realidades claves e inherentes al proyecto social-histórico y político que representa hoy el (neo)liberalismo, convocando la idea de desarrollo sujeta a este marco, podrían reproducir y relegitimar de vuelta esquemas y dispositivos (mentales, políticos, de todo tipo) que sólo permiten llegar a la superficie de los problemas. Buena parte de las «críticas» recientes al neoliberalismo se han concentrado en cuestionar exclusivamente las políticas (policies), las cuales por definición son coyunturales, y no el núcleo neoliberal estratégico y estructural al cual las primeras están sujetas (politics de la economía política) (Puello-Socarrás, 2011). Esta problemática se puede tornar más polémica si no se apunta a superar el trasfondo de ciertas situaciones y legitimar (sabiéndolo o no) ciertas versiones aparentemente críticas del neoliberalismo, las cuales - en medio de la crisis ideológica y epistémica actual- han sido promovidas y apoyadas por círculos neoliberales (heterodoxos) como una forma de renovar las viejas visiones ortodoxas en tanto éstas resultan obsoletas ideológicamente e improductivas e impracticables políticamente para continuar adelante y sostener el proyecto neoliberal.

Activar una crítica radical -entiéndase: de raíz- al (neo)liberalismo resulta entonces una obligación. Existe la exigencia que tanto pronósticos como proyecciones sean articulados simultáneamente bajo una mirada dinámica y actualizada. Las alternativas contra-hegemónicas 
muchas veces omiten las capacidades del neoliberalismo, especialmente en el sentido de su reconstitución a partir, sobre todo, de la alienación ideológica y el ocultamiento sistemático de sus contradicciones.

Ensayar entonces una paleontología (politológica) sobre la idea de desarrollo, develando sus orígenes neoliberales más que una curiosidad ociosa, intenta ofrecer, utilizando una expresión de René Zabaleta Mercado, un horizonte de visibilidad renovado en relación con los recursos ideológicos y las praxis discursivas que han constituido la hegemonía neoliberal desde sus inicios y hasta el presente.

La provocación paleontológica pretende, por una parte, reconstruir los referentes ideológicos del neoliberalismo y sus ideas centrales y estratégicas; por otra parte, establecer hallazgos que no queden únicamente como vestigios fijados en la memoria (pre)histórica de un concepto, sino que motiven nuevas interpretaciones sobre la historia actual, al decir de Gramsci: la política.

La construcción de la idea de desarrollo/subdesarrollo no solamente ha activado, parafraseando a Lukes, un poder para cambiar situaciones sociales y hacerlas funcionales al modo de producción y reproducción de relaciones sociales (económicas, políticas, culturales, etc.) hoy vigentes en el capitalismo; fundamentalmente, el desarrollo ejerce un poder sobre las transformaciones de la sociedad en las estructuras del capitalismo, convocando una dominación compleja y sistémica. Esta idea entonces no ha derivado simplemente en un contenido específico para el debate del desarrollo. Adicionalmente, ha impuesto de entrada los márgenes y las reglas (políticas, económicas, discursivas, epistémicas, etc.) sobre la discusión del desarrollo y, en esta forma, constriñe notablemente las posibilidades para su superación. Este horizonte significa la decisión de reconstruir socialmente y reconstituir políticamente proyectos alternos y nativos de manera auténtica, alternativos, en distintos territorios existenciales del llamado Sur global pero especialmente en nuestra América, des-institucionalizando y destituyendo económico-políticamente el proyecto neoliberal. 


\section{BIBLIOGRAFÍA}

Arndt, Heinz (1972), «Development Economics Before 1945», en Jagdish Bhagwati y Richard Eckaus (eds.), Development and Planning. Essays in Honour of Paul Rosenstein Rodan, Oxon, Routledge. (1987), Economic Development: The History of an Idea, Chicago, Chicago University Press.

Вавв, Sarah (2009), Beyond the Development Banks: Washington Politics, World Poverty and the Wealth of the Nations, Chicago, Chicago University Press.

Bauer, Peter (abril de 1958, 1959), Paper presented at the Discussions at the 9th Meeting of the Mont-Pèrelin Society, Princeton, Nueva Jersey,EUA.

Birdsall, Nancy, Augusto de la Torre y Felipe Valencia (2011), «The Washington Consensus. Assesing Damage Brand», en José Antonio Ocampo y Jaime Ros (eds.), The Oxford Handbook of Latin American Economics, Oxford, Oxford University Press.

Boron, Atilio (2008), Socialismo siglo XXI. ¿Hay vida después del neoliberalismo?, Buenos Aires, Luxemburg.

Byres, Terence (2006), «Agriculture and Development. Towards a Critique of the 'New Neoclassical Development Economics' and 'Neoclassical Neo-Populism'», en Ben Fine y K. S. Jomo (eds.), The New Development Economics after the Washington Consensus, Nueva Delhi, Tulika Books.

Coraggio, José Luis (2014), «Presentación de textos latinoamericanos», en José Luis Coraggio y Jean-Louis Laville (eds.), Reinventar la izquierda en el siglo XXI: Hacia un diálogo Norte-Sur, Los Polvorines, Universidad Nacional General Sarmiento.

Cypher, James (2011), «Teorías del desarrollo: una perspectiva económica crítica», en Henry Veltmeyer, Ivonne Farah e Igor Ampuero (eds.), Herramientas para el cambio: Manual para los estudios criticos del desarrollo, La Paz, Universidad Mayor de San Andrés.

Escobar, Arturo (2005), «El 'postdesarrollo' como concepto y práctica social», en Daniel Mato (ed.), Políticas de economía, ambiente 
y sociedad en tiempos de globalización, Caracas, Universidad Central de Venezuela.

(2007), La invención del Tercer Mundo. Construcción y deconstrucción del desarrollo, Caracas, Fundación Editorial El perro y la rana.

(2014), «De la crítica al desarrollismo al pensamiento sobre otra economía: pluriverso y pensamiento relacional», en José Luis Coraggio y Jean-Louis Laville (eds.), Reinventar la izquierda en el siglo XXI: Hacia un diálogo Norte-Sur, Los Polvorines, Universidad Nacional General Sarmiento.

Esteva, Gustavo (1996), «Desarrollo», en Wolfang Sachs (ed.), Diccionario del desarrollo. Una guía del conocimiento como poder, Lima, Pratec.

González Casanova, Pablo (1963), «Sociedad plural, colonialismo interno y desarrollo», América Latina. Revista del Centro Latinoamericano de Ciencias Sociales, vol. I, núm. 3.

(2006), «Colonialismo interno (una redefinición)», en Atilio Boron, Javier Amadeo y Sabrina González (eds.), La teoría marxista hoy. Problemas y perspectivas, Buenos Aires, clacso.

Harvey, David (2004), «El 'nuevo' imperialismo. Acumulación por desposesión», en Leo Panitch y Colin Leys (eds.), Socialist Register. El nuevo desafío imperial, Buenos Aires, clacso.

HAYEk, Friedrich (1952), La contrarrevolución de la ciencia. Estudios sobre el abuso de la razón, Madrid, Unión Editorial.

Jessop, Bob (1993), «'Towards a Shumpeterian Workfare State? Preliminary Remarks on Post-Fordist Political Economy», Studies in Political Economy, primavera, núm. 40.

LAL, Deepak (2012), «Is the Washington Consensus Dead?», cato Journal, vol. 32, núm. 3.

Mont-Pèlerin, Society (2005), «Inventory of the General Meeting Files (1947-1998)», en Inventories of the Liberal Archief, Ghent, Mont Pèlerin Society.

Newsletter Austrian Economics (1993), «F. A. Hayek (1899-1992): In Memoriam», Austrian Economics Newsletter, vol. 14, núm. 1. 
Parpart, Jane y Henry Veltmeyer (2011), «La evolución de una idea: estudios críticos del desarrollo», en Henry Veltmeyer, Ivonne Farah e Igor Ampuero (eds.), Herramientas para el cambio: Manual para los estudios críticos del desarrollo, La Paz, Universidad Mayor de San Andrés.

Peterson, William (1996), «A History of Mont Pèlerin Society by R. M. Hartwell (Book Review)», The Freeman, julio.

Plenwe, Dieter (2009), «The Origins of the Neoliberal Economic Development Discourse», en Phillip Mirowsky y Dieter Plehwe (eds.), The Road from Mont-Pèlerin. The Making of the Neoliberal Thought Collective, Cambridge, Harvard University Press. (2011), «Transnational Discourse Coalitions and Monetary Policy: Argentina and the Limited Powers of The 'Washington Consensus'», Journal of Critical Policy Studies, vol. 5, núm. 2.

Polanyi, Karl (1944), La gran transformación. Crítica del liberalismo económico, México, Fondo de Cultura Económica.

Prada Alcoreza, Raúl (2013), «La colonialidad como malla del sistema mundo capitalista», Bolpress.

Puello-Socarrás, José Francisco (2008), Nueva gramática del neoliberalismo. Itinerarios teóricos, trayectorias intelectuales, claves ideológicas, Bogotá, Universidad Nacional de Colombia. (2011), «A Brief History of Antineoliberalism. South American Political Economy and Development Paradigms in the Xxiтн Century», Ciência E Trópico Journal, vol. 35, núm. 1. (2013), «Ocho tesis sobre el neoliberalismo (1973-2013)», en Hernán Ramírez (ed.), O neoliberalismo sul-americano em clave transnacional: enraizamento, apogeu e crise, São Leopoldo, OikosUnisinos.

(2014), «El capitalismo del buen salvaje. Nuevo neoliberalismo e 'inclusión social'», Periferias. Revista de Ciencias Sociales, vol. 23, num. 22.

Puello-Socarrás, José Francisco y Angélica Gunturiz (2013), « ¿Social-neoliberalismo? Organismos multilaterales, crisis global y 
programas de transferencia monetaria condicionada», Política y Cultura, núm. 40 .

Rieter, Heinz y Matthias Schmolz (1933), «The Ideas of German Ordoliberalism 1938-1945: Pointing the Way to a New Economic Order», The European Journal of the History of Economic Thought 1, núm. 1.

Roffinelli, Gabriela y Néstor Kohan (2003), «Entrevista a Samir Amin», en www.rebelion.org (consultado en junio de 2014). Rostow, Walter (1961), Las etapas del crecimiento económico. Un manifiesto no comunista, México, Fondo de Cultura Económica.

SAchs, Wolfang (1996), Diccionario del desarrollo. Una guía del conocimiento como poder, Lima, Pratec. (1999), «The Archaeology of the Development Idea», en Planet Dialectics: Explorations in Enviroment and Development, Londres, Zed Books.

Shulak, Eugen-Maria y Herbert Unterköfler (2011), The Austrian School of Economics. A History of Its Ideas, Ambassadors, and Institutions, Auburn, Ludwig von Mises Institute.

Truman, Harry (1963), «Special Message to the Congress on Greece and Turkey: The Truman Doctrine. March 12, 1947», en National Archives and Records Administration (NARA) (ed.), Public Papers of the Presidents of the United States: Harry S. Truman, 1947, Washington, Best Books on.

Veltmeyer, Henry, Ivonne Farah e Igor Ampuero (eds.) (2011), Herramientas para el cambio: Manual para los estudios críticos del desarrollo, La Paz, Universidad Mayor de San Andrés. 